\title{
Genetic distance and the relationship with heterosis and reproductive behavior in tetraploid bahiagrass hybrids
}

\author{
F. Marcón • E. J. Martínez • G. R. Rodríguez •
}

A. L. Zilli • E. A. Brugnoli • Carlos A. Acuña (i)

Received: 21 February 2019 / Accepted: 21 May 2019

C) Springer Nature B.V. 2019

\begin{abstract}
Bahiagrass (Paspalum notatum Flüggé) is one of the main components of the South American grasslands, and it is cultivated for forage and turf around the world. At present, hybridization is the most common breeding technique for the species, and its goal is to obtain superior apomictic hybrids. The objective of the present study was to determine the relationship between heterosis, reproductive behavior, and genetic distances between parents in tetraploid bahiagrass. Genetic distance between 24 sexual tetraploid genotypes and 24 apomictic tetraploid genotypes of $P$. notatum was evaluated using simple sequence repeat (SSR) and inter simple sequence repeat (ISSR) markers. Crosses were made between parents with low, intermediate, or high genetic distances. Six families were generated. A marker linked to apospory in bahiagrass was used to determine segregation for mode of reproduction, and embryo sacs were characterized to estimate the level of apospory
\end{abstract}

Electronic supplementary material The online version of this article (https://doi.org/10.1007/s11032-019-0994-3) contains supplementary material, which is available to authorized users.

F. Marcón · E. J. Martínez · A. L. Zilli · E. A. Brugnoli • C. A. Acuña $(\square)$

Instituto de Botánica del Nordeste, Consejo Nacional de Investigaciones Científicas y Técnicas, Facultad de Ciencias Agrarias, Universidad Nacional del Nordeste, Sargento Cabral, 2131 Corrientes, Argentina

e-mail: cacuna@agr.unne.edu.ar expressivity. The ratio between sexual and aposporous hybrids ranged from 1:1 to 9:1 among families. Discontinuous variation for apospory expressivity was observed among hybrids, with either low or high levels being exhibited. A significant relationship between genetic distance and proportion of aposporous hybrids was observed. Heterosis was observed for all the evaluated traits and its level was dependent on the parental combination. Genetic distances between parents were related to heterosis, mainly for forage yield, which is the most important trait in forage species. Hence, molecular markers may be useful to predict the occurrence of heterosis for this trait.

Keywords Apomixis · Polyploidy · Genetic diversity · Molecular markers

\author{
G. R. Rodríguez \\ Instituto de Investigaciones en Ciencias Agrarias de Rosario, \\ Consejo Nacional de Investigaciones Científicas y Técnicas, \\ Facultad de Ciencias Agrarias, Universidad Nacional de Rosario, \\ Campo Experimental Villarino CC14, Zavalla, S2123ZAA Santa \\ $\mathrm{Fe}$, Argentina
}




\section{Introduction}

Apomixis, asexual reproduction through seed, has been reported in more than 125 forage grass species (Bashaw and Hanna 1990; Miles 2007), including those with greater economic value for cattle production in the tropics and subtropics, such as species of Brachiaria, Panicum, Cenchrus, and Paspalum (Moser et al. 2004; Jank et al. 2014). Apomixis allows to faithfully propagate heterozygous genotypes, which provides the opportunity to exploit heterosis (Miles 2007).

Heterosis is the superiority in performance of hybrid individuals compared with their parents, and this can be measured as the difference between the performance of the hybrid and the average performance of its parents (mid-parent heterosis); or as the difference between the performance of the hybrid and the performance of the better parent (high-parent heterosis) (Fehr 1991).

Heterosis has been extensively studied in sexual crop species (Coors and Pandey 1999), where the generation of hybrids produced a dramatic increase in yield (Duvick 1999). In maize (Zea mays) and sunflower (Helianthus annuиs), hybrids yielded, respectively, $15 \%$ and $50 \%$ more than superior open-pollinated varieties (Duvick 1999). In rice (Oryza sativa), hybrids exhibit around 20-30\% more yield than the best pure line cultivars (Fu et al. 2014). However, not all parental combinations maximize the level of heterosis in the progeny, which suggests that the particular combination of parents plays an important role (Chen 2010). East (1936) noted that the degree of heterosis in hybrids is proportional to the genetic difference between the two parental strains. In other words, the level of heterosis increases as the genetic distance between parents increases (Poehlman and Sleper 1995; Kaeppler 2012). Furthermore, Moll et al. (1965) demonstrated that there is an optimum level of genetic distance, and beyond this level, heterosis declines due to lack of adaptation of one or both parents or fertility problems.

In apomictic species, heterosis has been scarcely studied, even though apomixis provides enormous opportunities to exploit hybrid vigor, since maintenance of parental lines and formation of $F_{1}$ hybrids each year is unnecessary. The primary advantage of apomixis is that traits of interest in apomictic hybrids are fixed and remain unchanged over generations (Hanna and Bashaw 1987). Another advantage is that seed of a superior apomictic $\mathrm{F}_{1}$ hybrid can be multiplied directly for further evaluation (Hanna 1995). This allows greater efficiency and more rapid release of new cultivars, since inbred parental lines do not need to be developed (Evers and Burson 2004).

The development of molecular markers such as RAPDs, AFLPs, ISSRs, and SSRs has allowed measurement of genetic diversity among individuals with greater precision (Melchinger 1999; Xangsayasane et al. 2010; Wegary et al. 2012). This technology represents an attractive tool to predict parent genetic diversity and occurrence of heterosis in the progenies. Nevertheless, the results obtained using molecular markers as predictors of heterosis in crops have been inconsistent. In maize and rice, it was observed that SSR markers were effective to identify heterotic groups and predict heterosis (Zhang et al. 1994; Reif et al. 2003). Crosses between genetically distant parents of maize and rice resulted in hybrids with greater grain yield. In alfalfa (Medicago sativa), AFLP and SSR markers were used to calculate genetic distance among genotypes of the subspecies sativa and falcata and its correlation with biomass yield heterosis. However, genetic distance was not correlated with heterosis, and also markers failed to group genotypes belonging to the same subspecies (Riday et al. 2003). In contrast, in Panicum virgatum the use of RFLP markers differentiated two groups of genotypes adapted to two contrasting environments (Missaoui et al. 2006), which when crossed resulted in progenies with greater vigor than those progenies obtained by crosses between genotypes of the same group (Vogel and Mitchell 2008). All these results indicate that molecular markers could be effectively used to differentiate genetic distant groups, and in some cases, for selecting parental combinations to generate superior progenies.

Genetic improvement of apomictic species is currently based mainly on selection of natural ecotypes with superior agronomic characteristics (Vogel and Burson 2004; Blount and Acuña 2009). This breeding method has been very successful in species with high diversity; however, it is limited by its inability to generate novel genotypes that combine multiple traits of interest (Miles 2007). Hybridization arose as an alternative breeding method for apomictic species following the development of sexual genotypes at the same ploidy level (Burton and Forbes Jr 1960; Bashaw 1962; Smith 1972; Swenne et al. 1981). Hybridization allowed the creation of hybrid progenies variable for mode of reproduction and agronomic traits (Miles and do Valle 1996; Vogel and Burson 2004; Acuña et al. 2009). 
The genus Paspalum contains about 310 species native to the New World (Morrone et al. 2012) and many of the characterized species are apomictic. Bahiagrass, Paspalum notatum Flüggé, stands out among the species of the genus because of its dominance in rangelands of South America and its uses as forage and utility turf around the world (Gates et al. 2004). P. notatum includes polyploids that reproduce by apomixis and diploids that reproduce sexually. The tetraploid cytotype $(2 n=4 x=40)$ predominates in nature (Ortiz et al. 2013). Apomixis in bahiagrass is inherited as a single dominant gene with distorted segregation (Martínez et al. 2001). Creation of experimental sexual tetraploid genotypes by doubling the chromosomes of sexual diploids (Burton and Forbes Jr 1960; Quarin et al. 2001; Quesenberry et al. 2010), the knowledge of the inheritance of apospory and the identification of molecular markers completely linked to apospory in bahiagrass (Martínez et al. 2003; Stein et al. 2007) have allowed the development of breeding programs at the tetraploid level (Ortiz et al. 2013). Novel hybrids have been generated crossing experimental sexual tetraploid genotypes and apomictic tetraploid ecotypes. Around $10 \%$ of these hybrids inherited the apomixis trait with a high level of expression and, some of them exhibited superior agronomic and morphological characteristics that were fixed (Acuña et al. 2011; Zilli et al. 2015). Despite this, the probability of obtaining highly apomictic superior hybrids is low, and thus, also the efficiency of the breeding technique. However, there is evidence that the occurrence of heterosis and the proportion of segregation for mode of reproduction depend on parent combination (Acuña et al. 2011; Zilli et al. 2015; Novo et al. 2017).

Considering the importance of heterosis for breeding apomictic species and the possibility to generate hybrids between sexual and apomictic bahiagrass genotypes, the ability to predict heterosis becomes an attractive goal. This permits selecting parents more efficiently and increases the probability to obtain superior hybrids fixed by apomixis. The objectives of this research were to (i) estimate genetic distance between sexual and apomictic tetraploid genotypes using SSR and ISSR markers, (ii) select sexual and apomictic parents with low, intermediate, or high genetic distance and generate hybrids between them, (iii) evaluate the reproductive behavior of the resulting hybrids and its relation to genetic distance, (iv) determine the occurrence of heterosis for several agronomic and morphological traits, and (v) evaluate the relationship between genetic distance and heterosis.

\section{Materials and methods}

\section{Plant material}

A group of 48 tetraploid clones of Paspalum notatum was used. Half of them were experimental sexual tetraploid genotypes, most of these deriving from a synthetic sexual tetraploid population previously generated by Zilli et al. (2018). This population was created by intercrossing 29 sexual $F_{1}$ hybrids, which, in turn, were generated by crossing three experimental sexual clones with ten apomictic ecotypes. In addition, the group of sexual plants was introgressed with a few sexual $F_{1}$ hybrids generated in a step previous to the generation of the sexual synthetic tetraploid population. The remaining 24 clones were natural or experimental apomictic tetraploid genotypes. The natural ecotypes were collected from different locations in South America. Some of the experimental genotypes were introduced from the University of Florida (Table S1) and the others were $F_{1}$ hybrids generated in Corrientes, Argentina (Zilli et al. 2015). All parental clones are highly heterozygous and hence $F_{1}$ hybrid progenies are heterogeneous.

Genetic distance between sexual and apomictic genotypes

Genetic distance of the 48 sexual and apomictic tetraploid genotypes of $P$. notatum were performed using SSR and ISSR molecular markers, to identify pairs of sexual and apomictic parents with low, intermediate, and high genetic distance.

Genomic DNA of each genotype was isolated from tillers apical meristem using the methodology described by Brugnoli et al. (2014). Genomic DNA integrity and concentration were estimated using known standards which were separated by electrophoresis in $1 \% \mathrm{w} / \mathrm{v}$ agarose gel in 1x TAE ( $40 \mathrm{mM}$ Tris-HCl, $5 \mathrm{mM}$ sodium acetate, $0.77 \mathrm{mM}$ EDTA, $\mathrm{pH}$ 8.0) at $40 \mathrm{~V}$ for $1 \mathrm{~h}$. Gels were stained with ethidium bromide $\left(1 \mu \mathrm{g} \mathrm{mL}^{-1}\right)$ for $30 \mathrm{~min}$, and genomic DNA was visualized under ultraviolet light and photographed with GelDoc-It Imaging System (UVP, LLC). DNA samples were adjusted to $10 \mathrm{ng} \mu \mathrm{L}^{-1}$ for their use in polymerase chain reaction (PCR) amplifications. 
In both cases, a group of primers was screened for DNA amplification in order to identify those with greatest intensity of amplified markers and percentage of polymorphism. Eight SSR primers of $P$. notatum developed by Cidade et al. (2009) were employed in all genotypes. DNA amplifications were performed following the protocol described by Cidade et al. (2009) with minor modifications. Fragments PCR were amplified using a thermal cycler Bio-Rad (My Cycler ${ }^{\mathrm{TM}}$ ) in $25 \mu \mathrm{L}$ reaction volume, containing $20 \mathrm{ng}$ of genomic DNA, 1x Taq polymerase reaction buffer, $0.15 \mathrm{mM}$ dNTPs, $0.8 \mu \mathrm{M}$ of each primer, and $1 \mathrm{U}$ of Taq DNA polymerase (Promega). Cycles began with $5 \mathrm{~min}$ at $94{ }^{\circ} \mathrm{C}$ followed by 5 cycles of $1 \mathrm{~min}$ at $94{ }^{\circ} \mathrm{C} ; 1 \mathrm{~min}$ at $65^{\circ} \mathrm{C}$ (decreasing $1{ }^{\circ} \mathrm{C}$ per cycle) and $1 \mathrm{~min}$ at $72^{\circ} \mathrm{C}$, followed by 25 cycles of $1 \mathrm{~min}$ at $94{ }^{\circ} \mathrm{C} ; 1 \mathrm{~min}$ at $60^{\circ} \mathrm{C}$ and $1 \mathrm{~min}$ at $72{ }^{\circ} \mathrm{C}$, and a final extension of $5 \mathrm{~min}$ at $72{ }^{\circ} \mathrm{C}$. Amplicons were separated by electrophoresis in $6 \% \mathrm{w} / \mathrm{v}$ denaturing polyacrylamide gels at $300 \mathrm{~W}$ for $3 \mathrm{~h}$. Gels were stained using 1x SYBR ${ }^{\text {TM }}$ Gold nucleic acid gel stain (Invitrogen), visualized by blue light using an UltraBright LED transilluminator LB-16 (Maestrogen), and band patterns were photographed for analysis using a Coolpix L120 (Nikon) camera.

Ten ISSR primers were used for PCR amplification following the protocol described by Zilli et al. (2015) at same conditions. The PCR products were separated in $2 \% \mathrm{w} / v$ agarose gel in $1 \mathrm{x}$ TAE (40 mM Tris- $\mathrm{HCl}, 5 \mathrm{mM}$ sodium acetate, $0.77 \mathrm{mM}$ EDTA, $\mathrm{pH} 8.0$ ) by electrophoresis at $70 \mathrm{~V}$ for $3 \mathrm{~h}$. The molecular profiles were stained with ethidium bromide $\left(1 \mu \mathrm{g} \mathrm{mL} L^{-1}\right)$, visualized under ultraviolet light, photographed, and stored for further analysis with GelDoc-It Imaging System (UVP, LLC).

SSR and ISSR markers were scored in a binary matrix with $1=$ presence and $0=$ absence. The molecular analysis was performed using the software Info-Gen (Balzarini and Di Rienzo 2013). Genetic distances between sexual and apomictic genotypes were quantified by the Jaccard's dissimilarity coefficient (1-S).

In addition, the molecular genetic distance generated by SSR and ISSR markers was compared by the Mantel test using Info-Gen (Balzarini and Di Rienzo 2013).

\section{Crosses}

Parental sexual or apomictic clones were selected based on the genetic distance estimated by SSR and ISSR markers. Three groups of two pairs each were established considering the genetic distance observed. Group I consisted of those genotype pairs with the lowest genetic distance, group II by genotypes with intermediate genetic distance and group III by individuals that exhibited the highest genetic distance.

Crosses were made in January 2015. The day prior to anthesis, rooted culms of each sexual parent bearing inflorescences were placed in a 1-L container with water in an artificial fog chamber that started misting the following day at $4 \mathrm{am}$. Anthesis started around 6 am and the high level of humidity prevented anther dehiscence. Anthers were removed using sharp, pointed tweezers. Emasculated inflorescences of the sexual plants were dusted with pollen from the desired apomictic male parent. Pollinated inflorescences were bagged to prevent contamination with pollen from undesired sources. The containers were then placed in a shaded and fresh part of the glasshouse where they stayed for $30 \mathrm{~d}$ after pollination. Inflorescences from the sexual parents were then manually threshed and seeds were separated using a seed blower (Seedburo Equipment Company 1022W).

\section{Reproductive behavior}

Seeds were scarified using 98\% sulfuric acid for $10 \mathrm{~min}$ and then sown in potting mix. Individual seedlings with three leaves were transplanted to seedling flats. After $30 \mathrm{~d}$ plants were transplanted to the field, spaced $1 \times$ $1 \mathrm{~m}$, in November 2015, on the campus of Facultad de Ciencias Agrarias, Universidad Nacional del Nordeste, Corrientes, Argentina.

DNA extraction from each hybrid was performed as described above. The RAPD primer UBC247, which generates a specific marker ( $377 \mathrm{bp}$ ) completely linked to the apospory trait in bahiagrass (Martínez et al. 2003) was used to classify the hybrids as aposporous or sexual. PCRs were performed following the protocol described by Martínez et al. (2003). The PCR products were separated in $2 \% \mathrm{w} / \mathrm{v}$ agarose gel in $1 \mathrm{x}$ TAE $(40 \mathrm{mM}$ Tris- $\mathrm{HCl}, 5 \mathrm{mM}$ sodium acetate, $0.77 \mathrm{mM}$ EDTA, $\mathrm{pH} 8.0$ ) by electrophoresis at $70 \mathrm{~V}$ for $3 \mathrm{~h}$. The PCR amplifications were visualized and photographed as described for the ISSR markers. Those hybrids that amplified the specific marker were classified as aposporous, while the hybrids that did not show it were classified as sexual.

Apospory expressivity was evaluated in those hybrids previously classified as aposporous by the RAPD marker. Inflorescences of each aposporous hybrid were 
fixed at anthesis in FAA (70\% ethanol, 37\% formaldehyde, and glacial acetic acid in the ratio 18:1:1). Pistils were dissected out and clarified using the method described by Zilli et al. (2015). A minimum of thirty pistils from at least two different inflorescences were observed using a differential interference contrast microscopy and photographed with a Leica EC3 camera. Ovules were classified according to the composition and structure of the embryo sacs as follows: (1) ovules with meiotic embryo sacs, which were characterized by bearing a single embryo sac containing the egg apparatus, the binucleated central cell, and a mass of antipodals at the chalaza; (2) ovules with multiple or single aposporous embryo sacs with the egg apparatus, the central cell, no antipodals, and variable size and position; (3) mixed ovules when both reduced and unreduced embryo sacs were present in the same ovule.

The level of apospory expressivity was calculated as the percentage of ovules with aposporous embryo sacs (2) and mixed ovules (3) over the total number of analyzed ovules. The aborted or immature ovules were not counted.

\section{Agronomic and morphological evaluations}

Twenty hybrids per family (120 total hybrids) and their parents were vegetatively propagated in a greenhouse, generating four clonal replicates for each genotype. On December 19, 2016, hybrids and their parents were transplanted to the field in $1 \times 1 \mathrm{~m}$, single-plant experimental units, in a randomized complete block design with four replications. A border row of bahiagrass plants was planted around the experiment. The experiment was located in Corrientes, Argentina ( $27^{\circ} 38^{\prime} \mathrm{S}, 58^{\circ} 44^{\prime} \mathrm{W}$ ). The soil type is classified as Argiudoll with $\mathrm{pH}$ 5.9, $1.1 \%$ organic matter and 22.06 ppm of phosphorus. Growth habit was estimated by measuring plant diameter and height. Plant diameter $(\mathrm{cm})$ was calculated as the average between the longest and shortest diameter of a given plant. This variable was measured in May 2017 and, January and April 2018. Plant height (cm) was measured from the base of the plant to the top of the canopy and was measured in March and December 2017. Leaf blade width (mm) at the widest point of the leaf blade and leaf blade length $(\mathrm{cm})$ was measured on the youngest fully expanded leaf. Each leaf trait was measured on two different tillers of each plant in January 2018.
Initial vigor was visually estimated on 22 March 2017 using a 1 to 5 scale, where 1 represented the plants exhibiting the least aboveground vigor, and 5 represented the plants with the greatest vigor. Plants were then cut to approximately $5 \mathrm{~cm}$ stubble height on 2 May 2017. Fall regrowth was estimated on June 9 using the scale described above. Frost tolerance was visually estimated on 20 July 2017 after one frost event occurred on July 18 , with temperature reaching $-3{ }^{\circ} \mathrm{C}$, using a 1 to 5 scale, where 1 was the least frost tolerant plants, and 5 was the most tolerant plant. Spring regrowth was estimated on December 9, 2017, using the same scale described for initial vigor. Forage yield was determined by harvesting individual plants at $5-\mathrm{cm}$ stubble height on May 2, 2017, January 9 and April 19, 2018. The fresh weight of the harvested material was recorded, and a subsample was collected and dried at $60{ }^{\circ} \mathrm{C}$ for $48 \mathrm{~h}$. The dry subsample was weighed (g) and the dry weight of harvested biomass was calculated. Flowering time was determined by making weekly observations until the complete emergence of inflorescences of all plants. This evaluation was performed during the spring 2017 and summer 2018.

Heterosis analysis

Genetic effects associated with the expression of agronomic and morphological traits were estimated to determine the proportion of hybrids exhibiting heterosis. Trait expression could be explained by the additive gene effects, which are associated with the gene or allele values, and by the genetic interaction effects that involve alleles of the same gene (dominance) or those of different genes (epistasis). For this analysis, we used the additive-dominance model described by Kearsey and Pooni (1996). This model suggests that the additive and dominance effects are expressed by the parent with greater $(\mathrm{P} 1)$ or lower $(\mathrm{P} 2)$ phenotypic expression of the character being studied, and the $\mathrm{F}_{1}$ hybrid (F1). In this way, the positive complete dominance effect (CD+) is attributed to the parent with greater phenotypic expression of the character, the negative complete dominance effect (CD-) is attributed to the parent with the lesser phenotypic expression. The additive genetic effect (Ad) is attributed to the parental mean value (MPV). To determine the genetic effects involved in the expression of the hybrid traits, Student's $t$ test was done, and the statistical significance of the hybrid value was compared with the MPV, P1, and P2. When F1 = MPV, the 
additive genetic effect is involved in the expression of the character; while MPV $<\mathrm{F} 1<\mathrm{P} 1$ (or MPV $>\mathrm{F} 1>$ $\mathrm{P} 2$ ), the genetic effect involved is the positive (or negative) partial dominance ( $\left.\mathrm{PD}+/ \mathrm{PD}^{-}\right)$. Moreover, if $\mathrm{F} 1=$ $\mathrm{P} 1$ (or F1 = P2) the genetic effect involved is the positive (or negative) complete dominance $\left(\mathrm{CD}+/ \mathrm{CD}^{-}\right)$, and when $\mathrm{F} 1>\mathrm{P} 1$ the genetic effect is positive overdominance (OD+) and if $\mathrm{F} 1<\mathrm{P} 2$ the effect involved is negative overdominance (OD-).

Once the genetic effects of the hybrids were determined, the proportion of superior hybrids was calculated. Those genotypes that exhibited positive partial dominance, positive complete dominance and positive overdominance were considered as superior hybrids.

Genetic distance among parents and its relationship with the reproductive behavior and heterosis

An independence chi-squared test was performed to evaluate the relationship between the genetic distances among parents and the number of aposporous hybrids, the number of hybrids with high apospory expressivity (> $80 \%$ of ovules with aposporous or mixed embryo sacs), and the number of superior hybrids.

This test is used to determine if there is a significant relationship between two qualitative traits by comparisons between the observed and expected data.

\section{Results}

Genetic distance, selection of parents, and crosses

Selection of sexual and apomictic parents was accomplished based on genetic distances. Two electrophoretic patterns can be observed in Fig. S1. A total of 120 SSR fragments were amplified, and 116 were polymorphic (97\%) (Table 1). In addition, 151 ISSR loci were amplified of which 146 were polymorphic (97\%) (Table 1). Genetic distances performed by SSR and ISSR varied from 0.18 to 0.79 and 0.08 to 0.70 , respectively. A positive correlation was found among SSR and ISSR markers $(r=0.5 ; p<0.001)$ (Fig. S2). These values allowed selection of sexual and apomictic genotypes corresponding to groups of crosses with low (0.27$0.38)$, intermediate $(0.45-0.55)$, or high $(0.60-0.74)$ genetic distance (Table 2).

A group of 120 tetraploid hybrids, 20 from each of six families, were generated by crossing sexual and apomictic genotypes with different genetic distances. Seed set on the female parent ranged between $12.3 \%$ and $46.7 \%$, with a mean of $29.8 \%$ (Table 2). Germination percentage of crosses at $15 \mathrm{~d}$ after sowing ranged from $27.7 \%$ to $63.5 \%$, with a mean of $49.7 \%$ (Table 2).

Reproductive behavior and its relationship with genetic distances among parents

The apospory linked marker (UBC247-377) (Martínez et al. 2003) was present in 31 of the 120 hybrids (Table 3). An overall ratio of 2.8 sexual to 1 aposporous hybrid was observed, ranging between 9:1 and 1:1 among crosses (Table 3).

Expressivity for apospory ranged from hybrids bearing aposporous embryo sacs in each analyzed ovule to

Table 1 Simple sequence repeat (SSR) and inter-simple sequence repeat (ISSR) molecular characterization of 24 sexual tetraploid genotypes and 24 apomictic tetraploid genotypes of $P$. notatum with different origins. Total number of loci (TL), number of polymorphic loci (PL), number of monomorphic loci (ML), proportion of polymorphic loci (PPL), and polymorphic information content (PIC) obtained for each primer

\begin{tabular}{|c|c|c|c|c|c|}
\hline Primer & $\mathrm{TL}$ & PL & ML & PPL & PIC \\
\hline \multicolumn{6}{|l|}{$S S R$} \\
\hline PN03-A5 & 12 & 12 & 0 & 100 & 0.22 \\
\hline PN03-A6 & 16 & 16 & 0 & 100 & 0.26 \\
\hline PN03-G8 & 9 & 8 & 1 & 88 & 0.26 \\
\hline PN03-G10 & 13 & 12 & 1 & 92 & 0.24 \\
\hline PN02-H7 & 13 & 11 & 2 & 85 & 0.23 \\
\hline PN03-H10 & 24 & 24 & 0 & 100 & 0.23 \\
\hline PA01-B7 & 11 & 11 & 0 & 100 & 0.31 \\
\hline PN02-F6A & 22 & 22 & 0 & 100 & 0.26 \\
\hline Total & 120 & 116 & 4 & - & - \\
\hline \multicolumn{6}{|l|}{ ISSR } \\
\hline$(\mathrm{AG})_{8}-\mathrm{GC}$ & 16 & 16 & 0 & 100 & 0.13 \\
\hline$(\mathrm{GA})_{8}-\mathrm{C}$ & 16 & 16 & 0 & 100 & 0.25 \\
\hline$(\mathrm{AG})_{8}-\mathrm{T}$ & 14 & 12 & 2 & 86 & 0.13 \\
\hline$(\mathrm{AC})_{8}-\mathrm{G}$ & 17 & 17 & 0 & 100 & 0.20 \\
\hline GAG- $(\mathrm{AC})_{7}$ & 14 & 12 & 2 & 86 & 0.23 \\
\hline$(\mathrm{GA})_{8^{-}}-\mathrm{TC}$ & 13 & 13 & 0 & 100 & 0.20 \\
\hline$(\mathrm{GA})_{8}-\mathrm{T}$ & 16 & 16 & 0 & 100 & 0.21 \\
\hline $\mathrm{CAG}-(\mathrm{CA})_{7}$ & 15 & 14 & 1 & 93 & 0.22 \\
\hline$(\mathrm{AG})_{8}-\mathrm{C}$ & 14 & 14 & 0 & 100 & 0.30 \\
\hline$(\mathrm{AC})_{8}-\mathrm{T}$ & 16 & 16 & 0 & 100 & 0.20 \\
\hline Total & 151 & 146 & 5 & - & - \\
\hline
\end{tabular}


Table 2 Genetic distances between sexual and apomictic parents of P. notatum generated by SSR and ISSR markers. Seed set and germination percentage of each cross combination

\begin{tabular}{|c|c|c|c|c|c|c|c|}
\hline \multicolumn{3}{|c|}{ Genetic distance } & \multicolumn{2}{|l|}{ Cross combination } & \multicolumn{3}{|c|}{ Hybrids } \\
\hline Group & SSR Jaccard (1-S) & ISSR Jaccard (1-S) & Sexual female parent & Apomictic male parent & ID & Seed set $\%$ & Germination \% \\
\hline Low & 0.38 & 0.27 & A48 & A33 & A & 12.3 & 47.0 \\
\hline Low & 0.34 & 0.36 & $\mathrm{~J} 13$ & $\mathrm{~J} 23$ & $\mathrm{~B}$ & 29.8 & 59.8 \\
\hline Intermediate & 0.54 & 0.54 & B19 10 & UF13 & $\mathrm{C}$ & 29.0 & 51.2 \\
\hline Intermediate & 0.55 & 0.45 & H13 2 & 4117 & $\mathrm{D}$ & 46.7 & 49.0 \\
\hline High & 0.74 & 0.60 & K29 10 & 4040 & $\mathrm{E}$ & 32.4 & 63.5 \\
\hline High & 0.65 & 0.62 & P45 2 & 4012 & $\mathrm{~F}$ & 28.7 & 27.7 \\
\hline Mean & & & & & & 29.8 & 49.7 \\
\hline
\end{tabular}

hybrids with only meiotically derived embryo sacs. It was observed that $16 \%$ of the hybrids did not have ovules bearing aposporous embryo sacs (Fig. 1). Low levels of expressivity (between 1 and 20\%) were observed for $3 \%$ of hybrids, $18 \%$ of the hybrids fell between 21 and $50 \%$ of expressivity, $6 \%$ of the hybrids exhibited between 51 , and $80 \%$ of expressivity, and $55 \%$ were in the upper fractions (between 81 and $100 \%$ of expressivity).

The relationship between the proportion of aposporous hybrids and apospory expressivity with genetic distances between parents was performed by the independence chi-squared test. The test indicated a significant $(p=0.002)$ relationship between the proportion of aposporous hybrids in each family and the genetic distances between parents (Fig. 2a). However, the level of apospory expressivity in aposporous hybrids was not

Table 3 List of families with low, intermediate or high genetic distances, number of sexual and aposporous hybrids, and ratio between sexual and aposporous hybrids

\begin{tabular}{lllll}
\hline \multicolumn{5}{l}{ Hybrids } \\
Genetic & $\begin{array}{l}\text { Cross } \\
\text { distance }\end{array}$ & Sexual & Aposporous & $\begin{array}{l}\text { Ratio sexual/ } \\
\text { aposporous }\end{array}$ \\
\hline Low & $\mathrm{A}$ & 18 & 2 & $9: 1$ \\
Low & $\mathrm{B}$ & 16 & 4 & $4: 1$ \\
Intermediate & $\mathrm{C}$ & 16 & 4 & $4: 1$ \\
Intermediate & $\mathrm{D}$ & 15 & 5 & $3: 1$ \\
High & $\mathrm{E}$ & 14 & 6 & $2.3: 1$ \\
High & $\mathrm{F}$ & 10 & 10 & $1: 1$ \\
Total & & 89 & 31 & $2.8: 1$ \\
\hline
\end{tabular}

related with the genetic distance between parents $(p=$ 0.148) (Fig. 2b).

Heterosis analysis

Genetic effects related to the expression of agronomical and morphological traits were determined in 6 families of $P$. notatum obtained from crosses among parents with low, intermediate and high genetic distance, with the objective to identify the proportion of hybrids that were superior to their parents. For forage yield, dominance effects were predominant at all three evaluation dates. Positive complete dominance effects (CD+) were observed between 2.5 and $32.4 \%$ of total hybrids, and the negative complete dominance effects $\left(\mathrm{CD}^{-}\right)$were observed in 21.6 to $54 \%$ of the hybrids (Table S2). Regarding to initial vigor and spring regrowth the CD - effects were predominant, varying between 25 and $45 \%$ and between 12.5 and $50 \%$, respectively (Table S2). In addition, for fall regrowth and frost

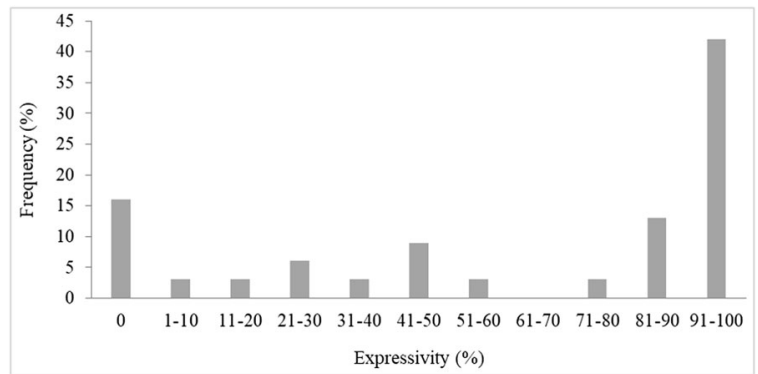

Fig. 1 Level of apospory expressivity for a group of 31 aposporous bahiagrass hybrids from 6 different sexual $\times$ apomictic families 

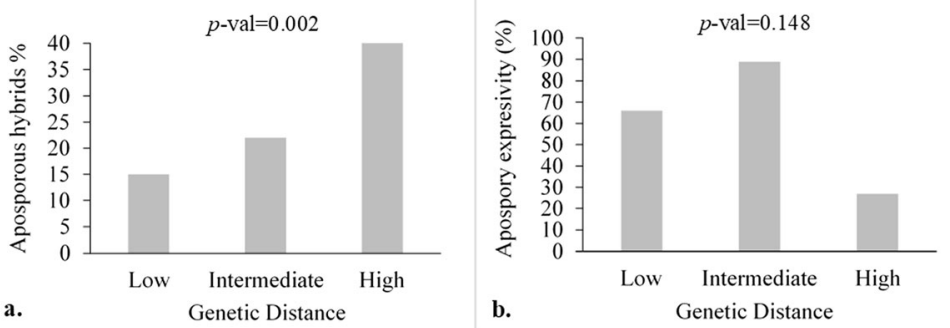

Fig. 2 a. Genetic distance among parents of $P$. notatum and its relationship with the percentage of aposporous hybrids. b. Relationship between genetic distance among parents and the percentage of apospory expressivity $(81-100 \%)$

tolerance, the positive and negative complete dominance effects were observed in most of the hybrids (Table S2).

Regarding plant height and diameter, the greater variation in the percentage of hybrids was observed for $\mathrm{CD}+$ and OD+. For both traits, the genetic effects observed on two different dates were similar, and the $\mathrm{CD}^{-}$ effects were predominant (2.5 to $55 \%$ of the hybrids) (Table S3). For flowering time, the greater variation was observed in hybrids with complete dominance. The proportion of hybrids with $\mathrm{CD}+$ was from 10 to $27.5 \%$, while the percentage of hybrids with $\mathrm{CD}^{-}$-varied between 5 and 45\% (Table S3). Genetic effect related to the expression of leaf blade length and leaf blade width exhibited a similar pattern (Table S3). In both cases, the greater variation was related to $\mathrm{CD}-(2.5$ to $22.5 \%$ of the hybrids), whereas from 2.5 to $19.4 \%$ of hybrids presented $\mathrm{CD}+$. In addition, leaf blade length exhibited greater OD- than leaf width (Table S3).

Heterosis and its relationship with genetic distances among parents

Those hybrids that in the genetic effect analysis exhibited positive partial dominance, positive complete dominance, and positive overdominance were considered as heterotic hybrids. Also, those hybrids whose genetic effects could not be determined were not counted. The fraction of hybrids that displayed heterosis was highly variable for the evaluated traits. For example, for summer forage yield, the proportion of hybrids exhibiting heterosis ranging from 5 to $60 \%$ while for fall forage yield was greater than $60 \%$ (Table 4). The proportion of hybrids displaying heterosis for initial vigor was from 6 to $15 \%$, and for spring regrowth varied between 0 and $41 \%$. Regarding to fall regrowth, it was observed that $14-45 \%$ of hybrids exhibited heterosis, while for frost tolerance the proportion of superior hybrids were greater (29 to 67\%) (Table 4).

On the other hand, the proportion of superior hybrids was also variable for morphological and phenological traits. Plant height measured on March 2017 exhibited from 0 to $17 \%$ of superior hybrids; however in December 2017, the proportion of superior hybrids varied between 5 and $52 \%$ (Table 5). The proportion of superior hybrids observed for plant diameter on May 2017 was 33\%, while for January 2018 and April 2018 were from 5 to $40 \%$ (Table 5). Regarding to leaf blade length and leaf blade width similar proportion of superior hybrids were

Table 4 Proportion of superior hybrids for agronomical traits and its relationship with the genetic distances among parents

\begin{tabular}{|c|c|c|c|c|c|c|c|}
\hline \multirow[t]{3}{*}{ Genetic distance } & \multicolumn{7}{|c|}{ Mid-parent heterosis (\%) } \\
\hline & \multicolumn{3}{|c|}{ Forage yield } & \multirow{2}{*}{$\begin{array}{l}\text { Initial vigor } \\
\text { March } 2017\end{array}$} & \multirow{2}{*}{$\begin{array}{l}\text { Fall regrowth } \\
\text { June } 2017\end{array}$} & \multirow{2}{*}{$\begin{array}{l}\text { Frost tolerance } \\
\text { July } 2017\end{array}$} & \multirow{2}{*}{$\begin{array}{l}\text { Spring regrowth } \\
\text { December } 2017\end{array}$} \\
\hline & May 2017 & January 2018 & April 2018 & & & & \\
\hline Low & 6 & 67 & 5 & 15 & 14 & 30 & 0 \\
\hline Intermediate & 12 & 67 & 31 & 6 & 0 & 67 & 27 \\
\hline High & 25 & 60 & 60 & 8 & 45 & 29 & 41 \\
\hline$p$ value* & 0.034 & 0.999 & 0.022 & 0.931 & 0.081 & 0.483 & 0.026 \\
\hline
\end{tabular}

* $p$ value for the independence chi-squared test 
Table 5 Proportion of superior hybrids for morphological and physiological traits and its relationship with the genetic distances among parents

\begin{tabular}{|c|c|c|c|c|c|c|c|c|}
\hline \multirow{3}{*}{$\begin{array}{l}\text { Genetic } \\
\text { distance }\end{array}$} & \multicolumn{8}{|c|}{ Mid-parent heterosis (\%) } \\
\hline & \multicolumn{2}{|l|}{ Plant height } & \multicolumn{3}{|c|}{ Plant diameter } & \multirow{2}{*}{$\begin{array}{l}\text { Leaf blade } \\
\text { length } \\
\text { January } 2018\end{array}$} & \multirow{2}{*}{$\begin{array}{l}\text { Leaf blade } \\
\text { width } \\
\text { January } 2018\end{array}$} & \multirow{2}{*}{$\begin{array}{l}\text { Flowering } \\
\text { time } \\
\text { December } \\
2017\end{array}$} \\
\hline & March 2017 & $\begin{array}{l}\text { December } \\
2017\end{array}$ & May 2017 & $\begin{array}{l}\text { January } \\
2018\end{array}$ & $\begin{array}{l}\text { April } \\
2018\end{array}$ & & & \\
\hline Low & 14 & 5 & 33 & 19 & 28 & 17 & 25 & 76 \\
\hline Intermediate & 0 & 18 & 33 & 40 & 36 & 38 & 17 & 3 \\
\hline High & 17 & 52 & 33 & 5 & 5 & 47 & 46 & 62 \\
\hline$p$ value* & 0.962 & 0.011 & 1 & 0.490 & 0.334 & 0.896 & 0.834 & 0.606 \\
\hline
\end{tabular}

*p value for the independence chi-squared test

observed (17 to 47\%), while for flowering time this proportion was highly variable (3 to $76 \%$ ) (Table 5).

The independence chi-squared test indicated a positive relationship between genetic distance among parents and heterosis for forage yield during two periods (March 2017 and April 2018), spring regrowth and plant height $(p<0.05)$ (Tables 4 and 5). In addition, a tendency to a positive relationship between genetic distance among parents and heterosis were observed for fall regrowth $(p<0.1)$ (Table 4). No significant relationship was observed between genetic distances and heterosis for the remainder of the morphological and agronomic traits.

\section{Discussion}

The opportunity of fixing superior hybrids via apomixis and the availability of sexual genotypes that can be crossed with apomictic genotypes in bahiagrass have encouraged us to develop a breeding scheme that allows exploitation of hybrid vigor.

Genetic distance between sexual and apomictic genotypes of bahiagrass was determined using SSR and ISSR molecular markers. The eight SSR primers amplified numerous markers with a high level of polymorphism. This technique allowed determination of the genetic variability among genotypes and identified pairs of crosses with different genetic distances for further evaluation of its relationship with heterosis. SSR results were similar to those reported by Cidade et al. (2009), where 11 primers amplified 87 polymorphic markers that allowed determination of the diversity among a group of 25 genotypes of $P$. notatum collected in Brazil. SSR markers were performed for genetic diversity analysis in other forage species, such as Panicum maximum and Medicago sativa. In P. maximum, 13 SSR primers amplified a total of 190 polymorphic markers, which allowed establishing the genetic relationships among 77 genotypes from East Africa (Ebina et al. 2007). In addition, this molecular marker has been effective in major crops such as maize (Wegary et al. 2012), sunflower (Usatov et al. 2014), and rice (Liu and $\mathrm{Wu}$ 1998). For instance, in maize, 40 SSR primers detected 169 polymorphic markers, which allowed the grouping of 15 inbred lines according to the genetic distance among them (Wegary et al. 2012).

The ten ISSR markers used in this study were as efficient as the SSR markers, since they amplified 146 highly polymorphic markers. These markers have been used previously in the genus Paspalum. Reyno et al. (2012) determined the genetic diversity of 210 genotypes of $P$. notatum collected from different sites of Uruguay using three primers that amplified 29 markers. In P. simplex, Brugnoli et al. (2014) employed 10 ISSR primers that amplified 163 markers, which allowed to study the genetic variability between and within populations. This technique has been used in other forage species such as Panicum coloratum var. makarikariense (Armando et al. 2015). They employed seven ISSR primers that amplified 103 polymorphic markers, which allowed establishment of the diversity among accessions of $P$. coloratum var. makarikariense. In addition, these markers have been effective in genetic diversity analysis of major crops, such as rice (Joshi et al. 2001), sunflower (Garayalde et al. 2011), and wheat (Pradeep Reddy et al. 2002).

Mode of reproduction of hybrids was defined using a RAPD marker completely linked to apospory in 
P. notatum (Martínez et al. 2003) due to its effectiveness, rapidity, and low cost (Zilli et al. 2015, 2018). The average ratio between sexual and aposporous hybrids was 2.8:1, what agrees with previous studies (Martínez et al. 2001; Stein et al. 2004; Acuña et al. 2009, 2011; Zilli et al. 2015). In most of the analyzed families, a greater-than-expected number of sexual hybrids was observed, except for one family (P45 $2 \times$ Q4012) that showed a 1:1 segregation ratio. A similar result was reported previously in bahiagrass by Zilli et al. (2015). The accumulated information related to sexual:aposporous segregation ratios indicates that it varies from 9:1 to $1: 1$.

Our results detected a relationship between genetic distance between parents and the proportion of aposporous hybrids in the progeny. As the genetic distance between parents increased, the proportion of aposporous hybrids also increased. These results may be explained by the hypothesis that hybridization between species with dissimilar ecological affinities and reproductive developmental program timing contributes to the induction of apomixis (Carman 1997). This hypothesis suggests that the asynchronous expression of parental genes could lead to a disruption of the meiotic process causing a shift from sexual to apomictic reproduction. However, further studies are needed to confirm this hypothesis, considering that it fits better to interspecific crosses than to intraspecific crosses as it was done in our work. Another possible explanation for the increase in the proportion of aposporous hybrids with the increase of the genetic distances among parents could be related with the inheritance of the apomixis trait. It was suggested that this trait is of qualitative inheritance which expression is controlled by a dominant Mendelian factor (Miles 2007); however, at present, there are many candidate genes under evaluation that may have a partial or modifying role in the expression of the trait (Mancini et al. 2018). Our results may be indicating that the expression of apomixis is a quantitative trait where many genes are taking part since genetic differences between parents are related to the segregation of this trait.

Hybrids of all evaluated families exhibited a discontinuous variation of apospory expressivity that allowed identification of groups with high and low expressivity as reported in previous research (Acuña et al. 2009, 2011; Zilli et al. 2015), which may be indicating that apospory expressivity is controlled by a single major gene. We observed that apospory expressivity is not related to genetic distance between parents, so genetic distance may not be useful for predicting high apomixis expressivity. The identification of "this major gene" will be of great interest. Nonetheless, this work shows that crossing very distant parents ensure progenies with large number of aposporous hybrids, which increases the probabilities to find highly aposporous hybrids among them.

In this research, we observed heterosis for all the studied traits with variable proportions among families. These results are similar to those reported by Zilli et al. (2015), who found the occurrence of heterosis in 11 bahiagrass families resulting from crosses between 3 experimental sexual genotypes and 9 apomictic genotypes. High parent heterosis ranged among families between 0 and $62.5 \%$ in Zilli et al. (2015), while in our study heterosis ranged between 0 and $75 \%$, which includes hybrids superior or equal to the better parent. Acuña et al. (2011) evaluated heterosis in bahiagrass. Their results were similar to ours; however, Acuña et al. (2011) observed that some traits exhibited greater values (>90\%) since hybrids were compared with mid-parent means and not to the better parent. Heterosis has also been studied in other Paspalum species. For example, Novo et al. (2017) evaluated this phenomenon in interspecific hybrids obtained by crosses between a unique sexual genotype of $P$. plicatulum and 22 apomictic genotypes belonging to 12 different species of Plicatula group of Paspalum. They observed positive heterosis respect to the apomictic parent only for cold tolerance and cattle preference, which varied between $14 \%$ and $100 \%$, and $24 \%$ and $81 \%$, respectively. These results show that heterosis in apomictic species depends on the trait under study and the combination of parents.

The genetic basis of heterosis in sexual plants has been debated for over a century (Chen 2010). However, in apomictic species few studies have been done. In order to clarify the genetic basis of heterosis in apomictic species, in this work, we determined the genetic effects associated to the expression of some agronomic and morphological traits in bahiagrass. Our results indicate that the dominance effects were predominant for all evaluated traits. This indicates that in $P$. notatum the heterosis is mostly due to the accumulation of dominant, favorable alleles in the hybrids. To exploit hybrid vigor outstanding parents that provide favorable alleles with complete or partial dominance for the trait of interest are required. In Brachiaria, the most cultivated apomictic forage species in Brazil, similar results were reported by Matias et al. (2018). They reported that most of the agronomic traits under study presented dominance 
genetic effects. These results could be indicating that in apomictic species, heterosis is due to the accumulation of favorable, dominant alleles rather than to inter-allelic interactions.

In this study, molecular markers were used as a tool to predict the occurrence of heterosis in bahiagrass based on genetic distance between parents. Our results indicate that SSR and ISSR markers were effective to determine genetic distance among parents and, that they were useful to predict the occurrence of hybrid vigor, since a significant relationship between heterosis and genetic distance among parents was observed for 3 out of the 10 agronomic and morphological traits evaluated. Reif et al. (2003) reported in maize a highly significant correlation between genetic distance, estimated by SSR markers and heterosis for grain yield, while no correlation was found for other evaluated traits. In rice, Zhang et al. (2010) determined a significant relationship between genetic distance using ISSR markers and heterosis for grain yield on 47 parental combinations. In other study with rice, a significant correlation was observed between genetic distances determined using RFLPs and heterosis for grain yield, number of tillers per plant, and number of seeds per panicle (Zhang et al. 1994). In sunflower, Usatov et al. (2014) reported a significant correlation between genetic distance and heterosis only for grain yield.

These results are pointing out that in major crops as in forage species, the use of molecular markers as a tool to predict heterosis have been effective for some traits such as grain and forage yield. In the case of $P$. notatum, the possibility of predicting the occurrence of superior hybrids for forage yield is a huge advance because this trait is the most important in forage species. In addition, this study demonstrates that a breeding method based on genetic distance is more efficient than the traditional one since it ensures progenies with the greatest proportion of aposporous hybrids and a greater level of heterosis.

In conclusion, SSR and ISSR molecular markers were effective to determine genetic distance between sexual and apomictic tetraploid genotypes of $P$. notatum. Genetic distance estimated by both markers allows paring sexual and apomictic genotypes with low, intermediate, or high genetic distance. Segregation for mode of reproduction was highly variable and the proportion of aposporous hybrids was positively related to genetic distance between parents. Discontinuous variation of apospory expressivity was observed among hybrids; groups with high or low expressivity were identified. Generation of superior aposporous hybrids is possible in $P$. notatum in the first breeding cycle. The occurrence of heterosis was mostly associated to the dominance effects of the genes. Furthermore, the proportion of heterotic hybrids was dependent on the parental combination. A significant relationship was observed between genetic distance between parents and heterosis for some morpho-agronomic traits. In addition, the use of molecular markers to determine genetic distance among bahiagrass genotypes allowed the prediction of the occurrence of heterosis for forage yield, fall regrowth, and plant height.

Acknowledgments The authors thank Dr. John W. Miles for reviewing this manuscript before submission.

Funding information This research was carried out with funding from SGCyT-UNNE, CONICET, FONCYT, and PGG Wrightson Seeds.

\section{References}

Acuña CA, Blount AR, Quesenberry KH, Kenworthy KE, Hanna WW (2009) Bahiagrass tetraploid germplasm: reproductive and agronomic characterization of segregating progeny. Crop Sci 49:581-588

Acuña CA, Blount AR, Quesenberry KH, Kenworthy KE, Hanna WW (2011) Tetraploid bahiagrass hybrids: breeding technique, genetic variability and proportion of heterotic hybrids. Euphytica 179:227-235

Armando LV, Tomás MA, Garayalde AF, Carrera AD (2015) Assessing the genetic diversity of Panicum coloratum var. makarikariense using agro-morphological traits and microsatellite-based markers. Ann Appl Biol 167:373-386

Balzarini MG, Di Rienzo JA (2013) InfoGen versión 2013. FCA, Universidad Nacional de Córdoba, Argentina. http://www. info-gen.com.ar

Bashaw EC (1962) Apomixis and sexuality in buffel grass. Crop Sci 2:412-415

Bashaw EC, Hanna WW (1990) Apomictic reproduction. In: Chapman GP (ed) Reproduction versatility in grasses. Cambridge Univ. Press, Cambridge, pp 100-130

Blount AR, Acuña CA (2009) Bahiagrass. In: Singh RJ (ed) Genetic resources, chromosome engineering, and crop improvement series: forage crops, vol 5. CRC Press, Boca Raton, pp 81-101

Brugnoli EA, Urbani MH, Quarin CL, Zilli AL, Martínez EJ, Acuña CA (2014) Diversity in apomictic populations of Paspalum simplex Morong. Crop Sci 54:1656-1664

Burton GW, Forbes I Jr (1960) The genetics and manipulation of obligate apomixis in common bahiagrass (Paspalum notatum Flüggé). In: Skidmore CL et al (eds) Proc. 8th Internat Grassl Congr. Reading, England. 11-21 July 1960. Alden Press, Oxford, pp 66-71 
Carman JG (1997) Asynchronous expression of duplicate genes in angiosperms may cause apomixis, bispory, tetraspory, and polyembryony. Biol J Linn Soc 61:51-94

Chen ZJ (2010) Molecular mechanisms of polyploidy and hybrid vigor. Trends Plant Sci 15:57-71

Cidade FW, Souza-Chies TT, Batista LAR, Dall'Agnol M, Zucchi MI, Jungmann L, Souza AP (2009) Isolation and characterization of microsatellite loci in Paspalum notatum Flüggé (Poaceae). Conserv Genet 10:1977-1980

Coors JG, Pandey S (1999) The genetics and exploitation of heterosis in crops. ASA, CSSA, and SSSA, Madison, Wisconsin, USA

Duvick DN (1999) Heterosis: feeding people and protecting natural resources In: Coors JG, Pandey S (eds) The genetics and exploitation of Heterosis in crops. ASA, CSSA, SSSA, Madison, Wisconsin, USA. pp 19-29

East EM (1936) Heterosis Genetics 21:375-397

Ebina M, Kouki K, Tsuruta S, Akashi R, Yamamoto T, Takahara M, Inafuku M, Okumura K, Nakagawa H, Nakajima K (2007) Genetic relationship estimation in guinea grass (Panicum maximum Jacq.) assessed on the basis of simple sequence repeat markers. Grassl Sci 53:155-164

Evers GW, Burson BL (2004) Dallisgrass and other Paspalum species. In: Moser LE, Burson BL, Sollenberger LE (eds) Warm-season (C4) grasses. Agron. Monogr, vol 45. ASA, CSSA, SSSA, Madison, pp 681-713

Fehr W (1991) Principle of cultivar development: theory and technique. Agronomy books. Iowa State University Press

Fu D, Xiao M, Hayward A, Fu Y, Liu G, Jiang G, Zhang H (2014) Utilization of crop heterosis: a review. Euphytica 197:161173

Garayalde AF, Poverene M, Cantamutto M, Carrera AD (2011) Wild sunflower diversity in Argentina revealed by ISSR and SSR markers: an approach for conservation and breeding programmes. Ann Appl Biol 158:305-317

Gates RN, Quarin CL, Pedreira CGS (2004) Bahiagrass. In: Moser LE, Burson BL, Sollenberger LE (eds) Warm-season (C4) grasses. Agron. Monogr, vol 45. ASA, CSSA, SSSA, Madison, pp 651-680

Hanna WW (1995) Use of apomixis in cultivar development. Adv Agron 54:333-350

Hanna WW, Bashaw EC (1987) Apomixis: its identification and use in plant breeding. Crop Sci 27:1136-1139

Jank L, Barrios SC, do Valle CB, Simeão RM, Alves GF (2014) The value of improved pastures to Brazilian beef production. Crop Pasture Sci 65:1132-1137

Joshi SP, Bhave SG, Chowdari KV, Apte GS, Dhonukshe BL, Lalitha K, Ranjekar PK, Gupta VS (2001) Use of DNA markers in prediction of hybrid performance and heterosis for a three-line hybrid system in rice. Biochem Genet 39: $179-200$

Kaeppler S (2012) Heterosis: many genes, many mechanisms-end the search for an undiscovered unifying theory. ISRN Botany $1-12$

Kearsey MJ, Pooni HS (1996) The genetical analysis of quantitative traits. Chapman and Hall, London

Liu XC, Wu JL (1998) SSR heterogenic patterns of parents for marking and predicting heterosis in rice breeding. Mol Breed 4:263-268

Mancini M, Permingeat H, Colono C, Siena L, Pupilli F, Azzaro C, de Alencar Dusi DM, de Campos Carneiro VT, Podio M,
Seijo JG, González AM, Felitti SA, Ortiz JPA, Leblanc O, Pessino SC (2018) The MAP3K-coding QUI-GON JINN (QGJ) gene is essential to the formation of unreduced embryo sacs in Paspalum. Front Plant Sci 9:1547

Martínez EJ, Urbani MH, Quarin CL, Ortiz JP (2001) Inheritance of apospory in bahiagrass, Paspalum notatum. Hereditas 135:19-25

Martínez EJ, Hopp HE, Stein J, Ortiz JPA, Quarin CL (2003) Genetic characterization of apospory in tetraploid Paspalum notatum based on the identification of linked molecular markers. Mol Breed 12:319-327

Matias FI, Barrios SCL, Bearari LM, Meireles KGX, Mateus RG, do Amaral PNC, Alves GF, do Valle CD, Fritsche-Neto R (2018) Contribution of additive and dominance effects on agronomical and nutritional traits, and multivariate selection on Urochloa spp. hybrids. Crop Sci 58:1-15

Melchinger AE (1999) Genetic diversity and heterosis. In: Coors JG, Pandey S (eds) The genetics and exploitation of heterosis in crops. ASA, CSSA, and SSSA, Madison, pp 99-118

Miles JW (2007) Apomixis for cultivar development in tropical forage grasses. Crop Sci 47:238-249

Miles JW, do Valle CB (1996) Manipulation of apomixis in Brachiaria breeding. In: Miles JW et al. (eds) Brachiaria: Biology, agronomy, and improvement. CIAT, Cali, Colombia, and CNPGC/EMBRAPA, Campo Grande, MS, Brazil. pp 164-177

Missaoui AM, Paterson AH, Bouton JH (2006) Molecular markers for the classification of switchgrass (Panicum virgatum L.) germplasm and to assess genetic diversity in three synthetic switchgrass populations. Genet Resour Crop Evol 53:12911302

Moll RH, Lonnquist JH, Wlez Fortuno J, Johnson EC (1965) The relationship between heterosis and genetic divergence in maize. Genetics 52:139-144

Morrone O, Aagesen L, Scataglini MA, Salariato DL, Denham SS, Chemisquy MA, Sede SM, Giussani LM, Kellogg EA, Zuloaga FO (2012) Phylogeny of the Paniceae (Poaceae: Panicoideae): integrating plastid DNA sequences and morphology into a new classification. Cladistics 28:333-356

Moser LE, Burson BL, Sollenberger LE (2004) Warm-season (C4) grasses. Agronomy Monography 45. ASA, CSSA, SSSA, Madison, Wisconsin, USA

Novo PE, Acuña CA, Quarin CL, Urbani MH, Marcón F, Espinoza F (2017) Hybridization and heterosis in the Plicatula group of Paspalum. Euphytica 213:198-210

Ortiz JPA, Quarin CL, Pessino SC, Acuña CA, Martínez EJ, Espinoza F, Hojsgaard DH, Sartor ME, Cáceres ME, Pupilli F (2013) Harnessing apomictic reproduction in grasses: what we have learnt from Paspalum. Ann Bot 112:767-787

Poehlman JM, Sleper DA (1995) Breeding field crops. Iowa State University Press, Ames

Pradeep Reddy M, Sarla N, Siddiq EA (2002) Inter simple sequence repeat (ISSR) polymorphism and its application in plant breeding. Euphytica 128:9-17

Quarin CL, Espinoza F, Martínez EJ, Pessino SC, Bovo OA (2001) A rise of ploidy level induces the expression of apomixis in Paspalum notatum. Sex Plant Reprod 13:243249

Quesenberry KH, Dampier JM, Lee YY, Smith RL, Acuña CA (2010) Doubling the chromosome number of bahiagrass via tissue culture. Euphytica 175:43-50 
Reif JC, Melchinger AE, Xia XC, Warburton ML, Hoisington DA, Vasal SK, Srinivasan G, Bohn M, Frisch M (2003) Genetic distance based on simple sequence repeats and heterosis in tropical maize populations. Crop Sci 43:1275-1282

Reyno R, Narancio R, Speranza P, Do Canto J, López Carro B, Hernández P, Burgueño J, Real D, Dalla Rizza M (2012) Molecular and cytogenetic characterization of a collection of bahiagrass (Paspalum notatum Flügge) native to Uruguay. Genet Resour Crop Evol 59:1823-1832

Riday H, Brummer EC, Campbell TA, Luth D, Cazcarro PM (2003) Comparisons of genetic and morphological distance with heterosis between Medicago sativa subsp. sativa and subsp. falcata. Euphytica 131:37-45

Smith RL (1972) Sexual reproduction in Panicum maximum. Crop Sci 12:624-627

Stein J, Quarin CL, Martínez EJ, Pessino SC, Ortiz JPA (2004) Tetraploid races of Paspalum notatum show polysomic inheritance and preferential chromosome pairing around the apospory-controlling locus. Theor Appl Genet 109:186-191 144

Stein J, Pessino SC, Martínez EJ, Rodriguez MP, Siena LA, Quarin CL, Ortiz JPA (2007) A genetic map of tetraploid Paspalum notatum Flüggé (bahiagrass) based on single-dose molecular markers. Mol Breed 20:153-166

Swenne A, Louant BP, Dujardin M (1981) Induction par la colchicine de formes autotetraploides chez Brachiaria ruziziensis Germain et Evrard (Graminee). Agron Trop 36: 134-141

Usatov AV, Klimenko AI, Azarin KV, Gorbachenko OF, Markin NV, Tikhobaeva VE, Kolosov YA, Usatova OA, Bakoev S, Makarenko M, Getmantseva L (2014) The relationship between heterosis and genetic distances based on SSR markers in Helianthus annuus. Am J Agric Biol Sci 9:270-276
Vogel KP, Burson BL (2004) Breeding and genetics. In: Moser LE et al (eds) Warm-season (C4) grasses. Agronomy monography, vol 45. ASA, CSSA, SSSA, Madison, pp 5194

Vogel KP, Mitchell RB (2008) Heterosis in switchgrass: biomass yield in swards. Crop Sci 48:2159-2164

Wegary D, Vivek B, Labuschagne M (2012) Association of parental genetic distance with heterosis and specific combining ability in quality protein maize. Euphytica 191:205-216

Xangsayasane P, Xie F, Hernandez JE, Boirromeo TH (2010) Hybrid rice heterosis and genetic diversity of IRRI and Lao rice. Field Crop Res 117:18-23

Zhang Q, Gao YJ, Yang SH, Ragab RA, Saghai Maroof MA, Li ZB (1994) A diallel analysis of heterosis in elite hybrid rice based on RFLPs and microsatellites. Theor Appl Genet 89: 185-192

Zhang T, Ni X, Jiang K, Yang Q, Yang L, Wan X, Cao Y, Zheng J (2010) Relationship between heterosis and parental genetic distance based on molecular markers for functional genes related to yield traits in rice. Rice Sci 17:288-295

Zilli AL, Brugnoli EA, Marcón F, Billa MB, Rios EF, Martínez EJ, Acuña CA (2015) Heterosis and expressivity of apospory in tetraploid Bahiagrass hybrids. Crop Sci 55:1189-1201

Zilli AL, Acuña CA, Shulz RR, Brugnoli EA, Guidalevich V, Quarin CL, Martínez EJ (2018) Widening the gene pool of sexual tetraploid bahiagrass: generation and reproductive characterization of a sexual synthetic tetraploid population. Crop Sci 58:762-772

Publisher's note Springer Nature remains neutral with regard to jurisdictional claims in published maps and institutional affiliations. 